\title{
ANNOTATION
}

\section{The Work of the Medical Research Council}

THE report of the Medical Research Council for 1925-1926 gives, in a space necessarily all too restricted, an account of the various researches promoted by it during that period. In the introduction the principles on which the Council acts are clearly enunciated as the following quotation shows: "Financial assistance can have, and has had, inestimable value in promoting research work, but it cannot always command it. Successful work at the growing points of knowledge can only be done by men of the first quality, and their success is only reached through freedom. To use the power of money so as to limit or divert their work to particular objects not of their own choice would be in great measure to waste it. Only the pioneer workers themselves can judge how best and at what point to make their advance upon a problem, whether by frontal or by flank movement. It is they and no others who can lay down as they proceed the lines which the work, viewed as a whole, is to follow. The distributors of money can aid them greatly by giving them freedom and better equipment, and they can aid general progress greatly too, by bringing into fuller activity those investigators of the second rank who follow up and exploit the advances of the leaders." In addition the fixed policy of the Council has always been to leave to scientific workers whom they aid complete discretion to publish their results as and when they think proper in appropriate technical journals. If all Government grants had previously been made on these lines we venture to think that better results in research might have been achieved.

The Special Committee formed in the previous year on the physiology of vision is responsible for excellent work, some of which has already been noticed in our columns. This Committee has formed a special sub-committee to deal with the problems of the fighting services which sub-committee is engaged in examining the relation of visual acuity to shooting efficiency, and the relative importance of different visual factors in naval rangefinding. Other subjects at present being worked at are "glare," flicker, the effects of ocular fatigue in industrial occupations involving eye strain, and illumination.

The Council have also under the heading of diseases and anomalies of the eye, continued their support to Professor Karl Pearson and Dr. Julia Bell in their work on the inheritance of diseases and anomalies of the eye, and to Dr. Ida Mann in her work on some abnormal and pathological states of the human eye. Some of the work of the first-named authors was reviewed in our columns (Brit. Jl. of Ophthal., Vol. X, p. 413), while some of Dr. Mann's 
work has been published in this journal (Brit. Jl. of Ophthal., Vol. IX, p. 495 and Vol. XI, p. 99) and also in the Trans. of the Ophthal. Soc., U.K., Vol. XLV, p. 696.

From this brief catalogue our readers may. gain some idea of the scope of the Council's work in ophthalmology, but this is only a very small part of the work that is being carried on, and those of us who desire to gain some idea of the trend of modern research work are advised to obtain a copy of the report.

In conclusion the Council desire to express their indebtedness to the numerous men of science who have given freely of their time and thought to the work of the various Committees (a list of these follows). They point out, "that it is only right that the public who provide the funds that the Council administer should be aware of the nature of this part of the machinery by which economic and effective distribution of them is in large part assured. If the Council in the administration of their parliamentary grant-in-aid had to pay for expert advice upon any fair remunerative scale the cost of the scientific results attained would be indefinitely increased. The benefits given by the several Committees, morever, have far more than a commercial value. Their work is done through the free association of scientific men for the framing and supervision of the schemes of research with which they are chiefly concerned." physiology of vision is responsible for some excellent work, some of which has already been noticed in our columns. This Committee has formed a special sub-committee to deal with the problems of the fighting services which is engaged in examining the relation of visual acuity to shooting efficiency, and the relative importance of different visual factors in naval range-finding. Other subjects at present being worked at are "glare,"flicker, the effects of ocular fatigue in industrial occupations involving eye strain, and illumination.

\section{ABSTRACTS}

\section{I.-NEUROLOGY}

(I) Naffziger, Howard C. - A method for the localization of the brain tumours-the pineal shift. Surg. Gynec. and Obstetrics., April, 1925.

(1) In autopsies on cases of brain tumour, it is a common observation that the portion of brain in which a growth is situated, increases greatly in volume. This is due not only to the presence of the lesion itself but to an increase in the fluid content of the affected hemisphere. In consequence of this there 